\title{
Quality of life in adults with cystic fibrosis
}

\author{
J Congleton, M E Hodson, F Duncan-Skingle
}

\begin{abstract}
Background - Cystic fibrosis is an inherited condition with a high mortality and morbidity. The aims of this study were to assess quality of life in a population of adults with cystic fibrosis, to compare quality of life with published scores from a healthy population and other patient groups, and to examine the relation between quality of life and other measured clinical variables.
\end{abstract}

Methods - Patients over 16 years of age attending an adult cystic fibrosis outpatient clinic were surveyed at a time when they were clinically stable. A selfcomplete questionnaire was administered which comprised the Nottingham Health Profile (NHP) together with six additional questions related to cystic fibrosis.

Results - Completed questionnaires were obtained from 240 subjects (100 women) of median age 26 years (range 16-56). Mean (SD) forced expiratory volume in one second $\left(F E V_{1}\right)$ was $49(26) \%$ predicted, forced vital capacity (FVC) was 68 (26)\% predicted, and the $\mathrm{FEV}_{1}: \mathrm{FVC}$ ratio was 59 (16)\%. In this cross sectional study different patterns of perceived quality of life were seen in men and women. In part 1 of the NHP there was an age related trend compared with norms in men, with more distress/disability in the dimensions of emotion, sleep, and social isolation in the older age groups. In women there was no age related trend in the degree of distress/ disability compared with norms. The mean score was different from norms in the dimensions of pain, emotion and sleep. For the patients with cystic fibrosis as a whole the scores in part 1 were comparable with published scores of patients with minor non-acute conditions. Scores in part 2 of the NHP for men were different from norms in six of the seven areas of daily living (all except home life). For women the scores were different from norms in the areas of looking after the home, social life, hobbies, and holidays. There were correlations between several of the quality of life dimensions and other measured variables such as $\mathrm{FEV}_{1}$, breathlessness score, and the time spent on home treatment.

Conclusions - Men and women with cystic fibrosis have different patterns of perceived quality of life, and there is an age related trend of perceived quality of life in men in some dimensions. Quality of life scores in this group, as assessed by the NHP, are similar to those reported in sub- jects with minor non-acute conditions. (Thorax 1996;51:936-940)

Keywords: cystic fibrosis, quality of life.

Cystic fibrosis is an inherited disorder which occurs at a frequency of approximately 1:2000 to $1: 2500$ live births. ${ }^{\prime}$ In $193880 \%$ of babies born with cystic fibrosis died within the first year of life and very few survived to adulthood. ${ }^{2}$ With improved care life expectancy has increased dramatically and there are now estimated to be 6000 people with cystic fibrosis in the UK of whom 2000 are adults. ${ }^{3}$ In addition, it is estimated that by the year 2000 there will be equal proportions of children and adults with cystic fibrosis. ${ }^{4}$ However, morbidity remains high, primarily due to progressive suppurative lung disease, chronic airflow limitation, and progressive deterioration in respiratory function. The cost of both maintenance treatment and treatment of complications is high, ${ }^{5}$ and in health services throughout Europe there is increasing pressure to show health related economic gain of both established and new treatments. As far as we are aware, quality of life has not been assessed in a large group of adults with cystic fibrosis. The aims of this study were to record perceived quality of life in adults with cystic fibrosis as assessed by the Nottingham Health Profile, to compare quality of life in adults with cystic fibrosis with published values in healthy populations and other patient groups, and to examine whether there is a relation between clinical variables and quality of life.

\section{Methods}

All patients with cystic fibrosis aged more than 16 years who attended our adult cystic fibrosis clinic over a two year period were eligible for the study. Each patient had an "annual review" appointment at which they were asked to complete a questionnaire, providing they were clinically stable. The questionnaire comprised the Nottingham Health Profile (NHP), ${ }^{6}$ together with an in house supplement of six questions related to cystic fibrosis (appendix A), and was self completed with nondirectional guidance. The cystic fibrosis supplement was designed to assess time spent in hospital, time able to work, quantity of sputum produced, time spent on home treatment (physiotherapy and administration of nebulised drugs), and degree of breathlessness. The NHP is a self-complete general quality of life questionnaire designed to measure perceived health problems and the extent to which 
Table 1 Scores in part 1 of the Nottingham Health Profile expressed as a percentage of the mean score for a healthy population of the same sex and age group. (Quartiles in parentheses)

\begin{tabular}{|c|c|c|c|c|c|c|}
\hline & Energy & Pain & Emotion & Sleep & Social isolation & Physical mobility \\
\hline \multicolumn{7}{|c|}{$\operatorname{Men}(n=112)$} \\
\hline $\begin{array}{l}\text { Mean } \\
(\mathrm{Q} 1, \mathrm{Q} 3)\end{array}$ & $\begin{array}{l}355 \\
(0,600)\end{array}$ & $\begin{array}{l}156 \\
(0,0)\end{array}$ & $\begin{array}{l}135 \\
(0,259)\end{array}$ & $\begin{array}{l}172 \\
(0,219)\end{array}$ & $\begin{array}{l}233 \\
(0,0)\end{array}$ & $\begin{array}{l}499 \\
(0,688)\end{array}$ \\
\hline \multicolumn{7}{|c|}{ Women $(n=73)$} \\
\hline $\begin{array}{l}\text { Mean } \\
(\mathrm{Q} 1, \mathrm{Q} 3)\end{array}$ & $\begin{array}{l}157 \\
(0,367)\end{array}$ & $\begin{array}{l}174 \\
(0,0)\end{array}$ & $\begin{array}{l}86 \\
(0,147)\end{array}$ & $\begin{array}{l}110 \\
(0,134)\end{array}$ & $\begin{array}{l}125 \\
(0,0)\end{array}$ & $\begin{array}{l}461 \\
(0,579)\end{array}$ \\
\hline \multicolumn{7}{|c|}{ Difference from 100 (p values) } \\
\hline Men & $<0.05$ & $<0.001$ & NS & NS & $<0.01$ & NS \\
\hline Women & NS & $<0.001$ & $<0.01$ & $<0.05$ & NS & NS \\
\hline
\end{tabular}

Note $100=$ norm. High scores indicate more distress/disability.

$<20$ year olds excluded as no normal values available.

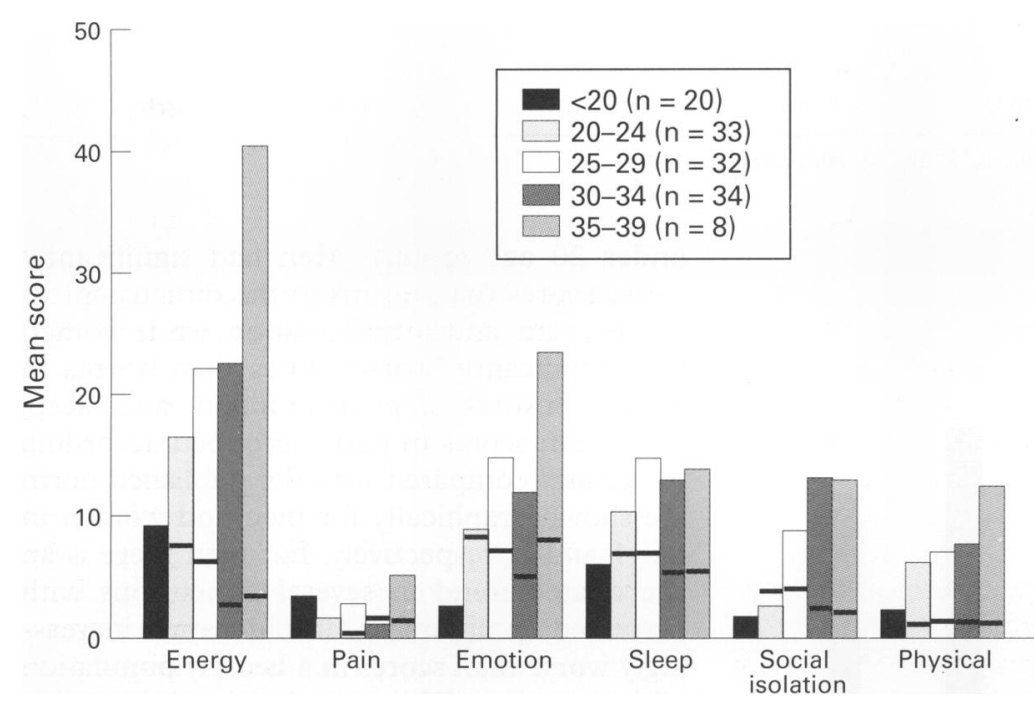

Figure 1 Mean scores in part 1 of the Nottingham Health Profile in men compared with norms (heavy horizontal lines). No norms are given for the $<20$ year age group.

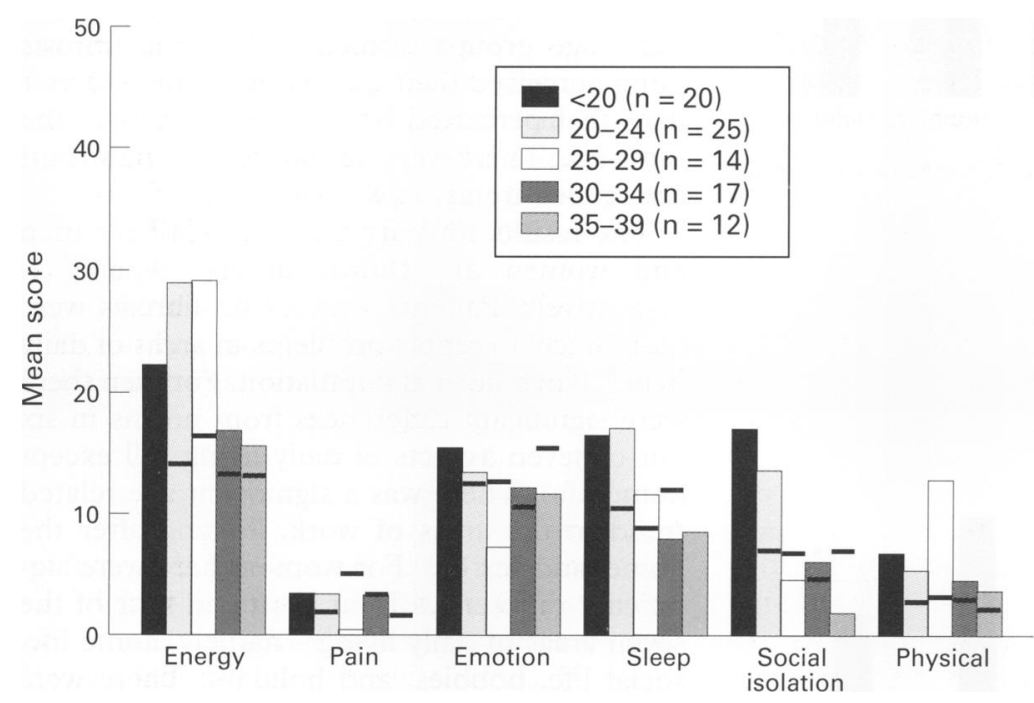

Figure 2 Mean scores in part 1 of the Nottingham Health Profile in women compared with norms (heavy horizontal lines). No norms are given for the $<20$ year age group.

these problems affect normal activities of daily life. It has been validated and tested for reliability and has previously been used to assess quality of life prior to and following heart-lung transplantation in patients with cystic fibrosis. ${ }^{7}$ Part 1 consists of weighted questions which assess perceived distress or disability in six dimensions: energy, pain, emotion, sleep, social isolation, and physical mobility. Part 2 examines which of seven areas of daily living are affected by disease by a "yes/no" response to the question: "Is your present state of health causing problems with your...............?" The seven areas of daily living assessed in part 2 are: employment, looking after the home, social life, home life (relationships with other people in the home), sex life, hobbies, and holidays. The mean score in a healthy population varies with age and sex, and norms for a healthy population have been published. ${ }^{8}$ Spirometric tests were performed on a dry wedge spirometer and the forced expiratory volume in one second $\left(\mathrm{FEV}_{1}\right) \%$ predicted, forced vital capacity (FVC) \% predicted, ${ }^{9} \mathrm{FEV}_{1}: \mathrm{FVC}$ ratio, and body mass index (weight/height ${ }^{2}$ ) were calculated.

\section{DATA ANALYSIS}

All statistical tests were performed two sided and the level of significance was set at $p$ $<0.05$. The quality of life data were not normally distributed and therefore nonparametric statistical methods were used. The median and interquartile range are presented in the tables, but mean values are presented in the figures to allow comparison with reference data which are presented as mean values in the original publications. ${ }^{8}{ }^{10}$ In order to assess the data the results were expressed as a percentage of the norm for that age and sex. To compare our data with the norms the distribution was tested for difference from $100 \%$ using a Wilcoxon matched pairs signed rank test for part 1 and a $\chi^{2}$ test for part 2 . In order to analyse age related trends the data were summarised using a frequency count as many of the scores were zero. Differences between age groups for parts 1 and 2 were tested using logistic ANOVA. Factor analysis showed that there was no additional information gained from question 2 of the cystic fibrosis supplement over question 1 (time in hospital and hours worked over the past three and 12 months, respectively) so the data from question 2 were ignored for the purpose of the analysis. Correlation between quality of life scores and clinical variables was assessed using Spearman's rank correlation coefficient.

\section{Results}

The subjects were the first 240 patients (100 women) who attended the outpatient clinic for their annual review appointment (the total clinic population is approximately 350 patients). Their median age was 27 years (range 16-56); mean (SD) $\mathrm{FEV}_{1}$ was 49 (26)\% predicted, mean FVC 68 (26)\% predicted, and the mean $\mathrm{FEV}_{1}: \mathrm{FVC}$ ratio was $59(16) \%$. 
Table 2 Correlation coefficients between clinical variables and scores on part 1 of the Nottingham Health Profile in all pateints with cystic fibrosis

\begin{tabular}{|c|c|c|c|c|c|c|c|}
\hline & $F E V_{1} \%$ & $B M I$ & $S O B$ & Sputum volume & Time on treatment & Time in hospital & Time able to work \\
\hline \multicolumn{8}{|c|}{ Energy } \\
\hline$r$ & -0.43 & -0.20 & 0.53 & 0.40 & 0.30 & 0.35 & -0.44 \\
\hline $\mathrm{p}$ & $<0.0001$ & $<0.001$ & $<0.0001$ & $<0.0001$ & $<0.0001$ & $<0.0001$ & $<0.0001$ \\
\hline \multicolumn{8}{|l|}{ Pain } \\
\hline$r$ & -0.43 & -0.02 & 0.27 & 0.19 & 0.28 & 0.15 & -0.21 \\
\hline $\mathrm{p}$ & $<0.0001$ & NS & $<0.0001$ & $<0.0001$ & $<0.0001$ & $<0.05$ & $<0.01$ \\
\hline \multicolumn{8}{|c|}{ Emotion } \\
\hline$r$ & -0.15 & -0.07 & 0.45 & 0.17 & 0.45 & 0.23 & -0.23 \\
\hline $\mathrm{p}$ & $<0.05$ & NS & $<0.0001$ & $<0.0001$ & $<0.0001$ & $<0.001$ & $<0.01$ \\
\hline \multicolumn{8}{|c|}{ Sleep } \\
\hline$r$ & -0.3 & -0.15 & 0.35 & 0.22 & 0.35 & 0.36 & -0.31 \\
\hline $\mathrm{p}$ & $<0.0001$ & $<0.05$ & $<0.0001$ & $<0.0001$ & $<0.0001$ & $<0.0001$ & $<0.0001$ \\
\hline \multicolumn{8}{|c|}{ Social isolation } \\
\hline$r$ & -0.17 & -0.04 & 0.38 & 0.29 & 0.38 & 0.24 & -0.23 \\
\hline $\mathrm{p}$ & $<0.01$ & NS & $<0.0001$ & $<0.0001$ & $<0.0001$ & $<0.001$ & $<0.01$ \\
\hline \multicolumn{8}{|c|}{ Physical mobility } \\
\hline$r$ & -0.51 & -0.30 & 0.61 & 0.35 & 0.62 & 0.42 & -0.45 \\
\hline $\mathrm{p}$ & $<0.0001$ & $<0.0001$ & $<0.0001$ & $<0.0001$ & $<0.0001$ & $<0.0001$ & $<0.0001$ \\
\hline
\end{tabular}

$\mathrm{FEV}_{1}=$ forced expiratory volume in one second; $\mathrm{BMI}=$ body mass index; SOB = breathlessness score.

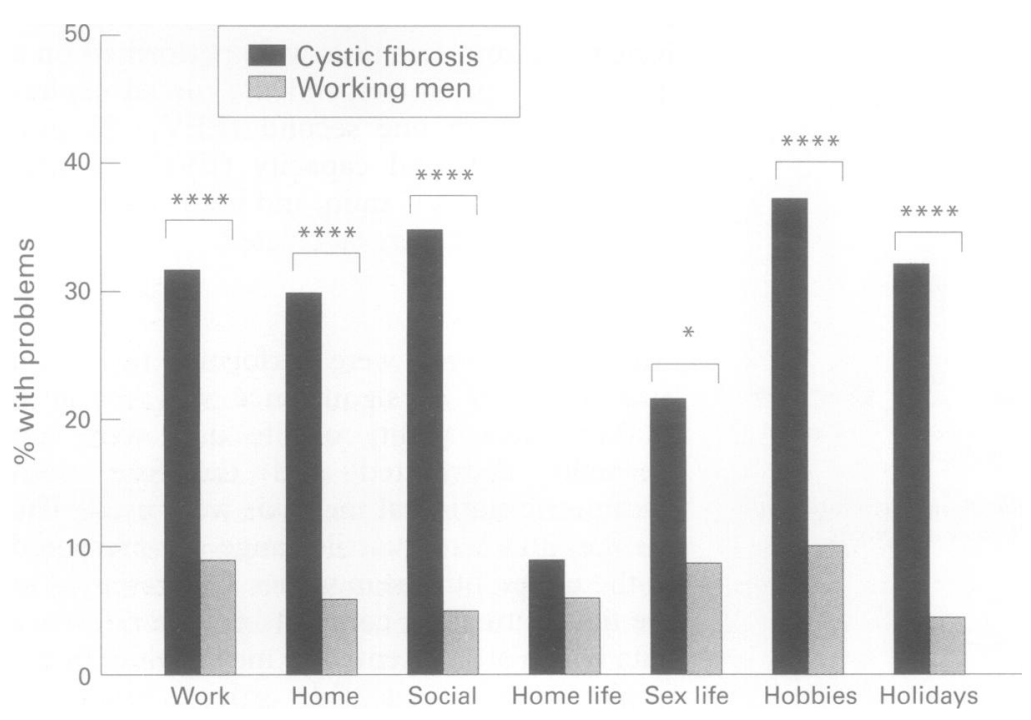

Figure 3 Scores in part 2 of the Nottingham Health Profile in men compared with norms. $\star_{p}<0.05 ; * * *_{p}<0.0001$.

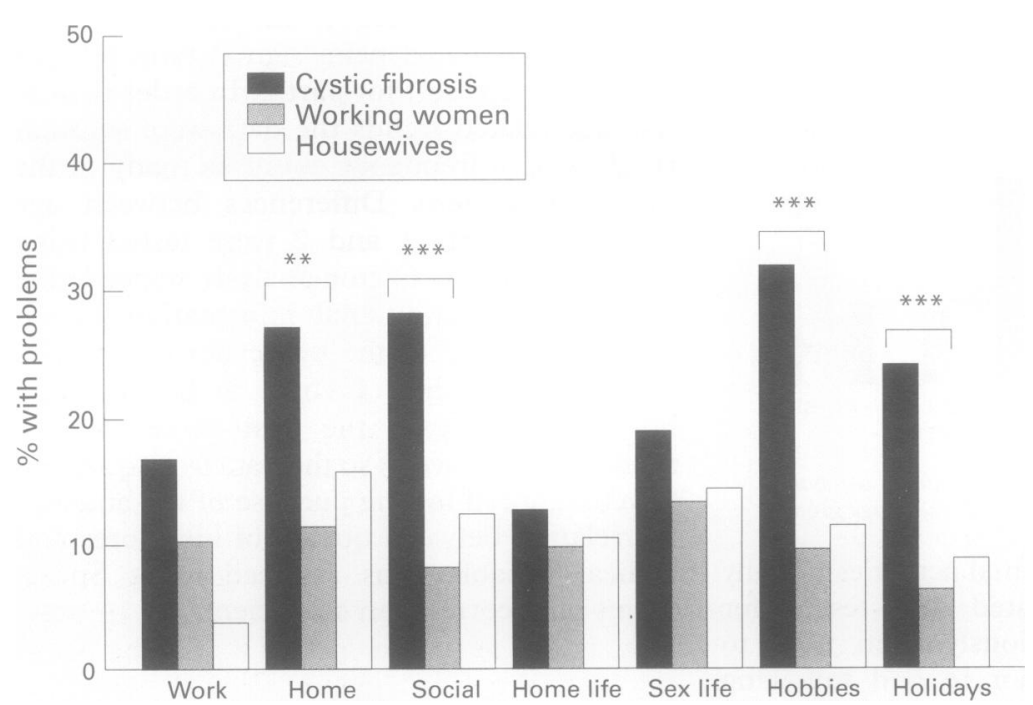

Figure 4 Scores in part 2 of the Nottingham Health Profile in women compared with norms. ${ }^{*} p<0.01 ;{ }^{* \star} \star_{p}<0.001$.

The scores in part 1 were compared with scores from a large community study of a healthy population. ${ }^{8}$ The data for each dimension were expressed as a percentage of the norm for that age and sex and are shown in table 1 (there are no published norms for the under 20 age group). Men had significantly worse scores than norms in the dimensions of energy, pain, and social isolation, while women had significantly worse scores than norms in the dimensions of pain, emotion, and sleep. The mean scores in part 1 grouped according to age and compared with the published norm are shown graphically for men and women in figs 1 and 2 , respectively. For men there is an age related trend in several dimensions with perceived quality of life in older men increasingly worse than scores in a healthy population of the same age. This age related trend was statistically significant in the dimensions of emotion, sleep, and social isolation. The same pattern was not seen in women; in fact, in the older age groups women with cystic fibrosis often perceived their quality of life to be better than that perceived by healthy subjects of the same age. There were no statistically significant age related trends in women.

The results for part 2 of the NHP for men and women are shown in figs 3 and 4 , respectively. Patients with cystic fibrosis were more likely to report problems in areas of daily living than a normal population. For men there were significant differences from norms in six out of seven aspects of daily living (all except home life). There was a significant age related trend in the areas of work, looking after the home, and sex life. For women there were significant differences from norms in four of the seven areas of daily living - namely, home life, social life, hobbies, and holidays. There were no statistically significant age related trends in women.

Correlation coefficients between scores for each of the dimensions in part 1 and the measured variables and responses to the cystic fibrosis supplement are shown in table 2 . There was a close correlation between the scores in many of the dimensions and all of the clinical variables except body mass index.

The scores in part 1 in the patients with cystic fibrosis were compared with scores published for populations with other conditions such as pregnancy at 18 weeks and 37 weeks, outpatients with fractures, patients with peripheral vascular disease, and patients with minor non-acute conditions such as varicose 


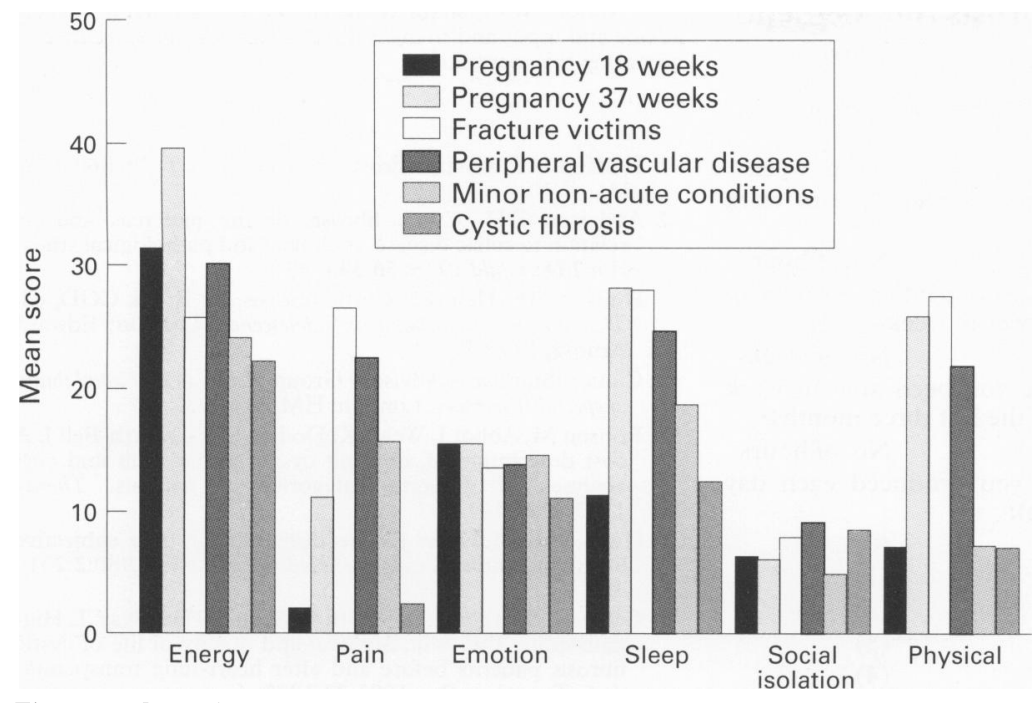

Figure 5 Scores in part 1 of the Nottingham Health Profile in all patients with cystic fibrosis compared with other conditions. veins and inguinal hernias. ${ }^{10}$ The mean scores are shown graphically in fig 5. They most closely approximate to those in minor nonacute conditions and were generally substantially lower than in the other groups. No formal statistical analysis was performed on these data.

\section{Discussion}

A general health questionnaire was chosen rather than a disease specific questionnaire because cystic fibrosis is a multisystem disease and, in addition, it was felt that a general measure would give a better indication of overall quality of life. The Nottingham Health Profile has been used in cystic fibrosis populations previously, ${ }^{71}$ and it therefore seemed appropriate to use it. It appears to be a useful tool. There was a strong correlation between several of the dimensions in part 1 and $\mathrm{FEV}_{1} \%$ predicted, breathlessness score, sputum production, time per day spent on treatment, time in hospital, and hours per day able to work. This strong correlation is notable because it is often not seen in other conditions such as chronic bronchitis and emphysema. A possible explanation is that, as patients with these latter conditions are older, they put less emphasis on physical mobility. There was no correlation with body mass index and it is possible that some patients with cystic fibrosis are happy being thinner than their clinical advisers would like them to be. Large improvements in quality of life as assessed by the NHP have been shown following heart-lung transplantation in patients with cystic fibrosis, ${ }^{7}$ and it remains to be seen whether differences in quality of life resulting from treatment that have significant but less dramatic clinical effects can be detected.

The difference in perceived quality of life between men and women is interesting and there are many possible explanations. We do not feel that it can be explained simply by sex related disease severity as the spirometric parameters were not different between men and women and there were similar numbers of both sexes in each age group. In addition, there were no differences in the degree of breathlessness, sputum production, and the time spent on treatment between men and women. It may be that women tend to develop better coping strategies and there are several hypotheses as to why this may be - for example, women may have lower expectations, some men may still feel that they should be the providers in society, women may be more likely to develop and maintain better family and social support networks, and a higher percentage of women with cystic fibrosis are married or in stable relationships than are men with cystic fibrosis. ${ }^{12}$

Overall, the perceived quality of life was high when compared with other groups which would be considered to have much less severe disease or even normal physiological states such as pregnancy. These scores in the cystic fibrosis population are undoubtedly skewed, probably due to the fact that most of the patients have been symptomatic from a young age and have adjusted well to the limitations of the disease. This highlights the fact that it is very difficult to compare quality of life in dissimilar groups of patients. One way of interpreting the relatively good quality of life is to conclude that the intensive treatment required for these patients is worthwhile as those who receive treatment perceive themselves to have a relatively good quality of life. However, we are concerned that a quality of life measure could be used to compare the value of treatment in different populations and that this would not be valid as the pre-intervention scores are not truly equivalent. Few would argue, for example, that the impact of troublesome varicose veins on an individual is in anyway comparable to the impact of a disease such as cystic fibrosis. The scale for a person who is used to being in good health appears to be greatly expanded and therefore measured improvement following procedures in minor conditions would be expected to be relatively large leading to a falsely low cost per unit of quality of life gained.

In conclusion, the Nottingham Health Profile appears to be a satisfactory tool for assessing quality of life in adults with cystic fibrosis. There is a strong relation between perceived quality of life and other measures of disease severity such as $\mathrm{FEV}_{1}$, breathlessness, and the time spent on home treatment. Men and women with cystic fibrosis have different patterns of perceived quality of life, the reaons for which have not been studied in this group. We warn against the danger of using such quality of life measures to attempt to compare different groups of patients in health economics planning exercises. 
Appendix A: Cystic Fibrosis Supplement

1. In the last 12 months: Score

(a) How much time have you spent in hospital? (answer in weeks)

No. of weeks

(b) How many hours have you been able to work each day (on average)?

No. of hours

2. (a) How much time have you spent in hospital in the last 3 months? (answer in weeks)

No. of weeks

(b) How many hours have you been able to work each day on average in the last three months?

No. of hours

3. How much sputum have you produced each day over the last week (tick one):

$\mathrm{Nil}$

An eggcup

Half a teacup

One teacup

More than a teacup

4. How many hours per day have you spent on your physiotherapy in the last week?

No. of hours

5. How many hours per day have you spent on your nebulizer treatment in the last week?

No. of hours

(Time spent on treatment $=$ score from Q4 45 )

6. Are you breathless

at rest?

dressing?

walking on the flat?

walking up hill?

not at all?
The authors are grateful to Jackie Turner for her statistical advice and input and thank Sally Hockley for her assistance in preparing this manuscript

1 Hodson ME. Cystic fibrosis. Postgrad Med f 1984;60:22533.

2 Andersen DH. Cystic fibrosis of the pancreas and its relation to celiac disease. A clinical and pathological study Am $\mathcal{F}$ Dis Child 1938; 56:344-99.

3 Hodson ME, Helms P. Cystic fibrosis. In: Brook CGD, ed The practice of medicine in adolescence. London: Edward Arnold, 1993:57-74.

4 Clinical Standards Advisory Group. Access to and availability of specialist services. London: HMSO, 1993.

5 Robson M, Abbot J, Webb K, Dodd M, Walsworth-Bell J. A cost description of an adult cystic fibrosis unit and cost analyses of different categories of patients. Thorax 1992;47:684-9.

6 Hunt SM, McEwen J. The development of a subjective health indicator. Sociology of Health and Illness 1980;2:231 46.

7 Caine N, Sharples LD, Smyth R, Scott J, Hathaway T, Hig ginbottom TW, et al. Survival and quality of life of cystic fibrosis patients before and after heart-lung transplantation. Transplant Proc 1991;23:1203-4.

8 Hunt SM, McEwen J, McKenna SP. Perceived health: age and sex comparisons in a community. $\mathcal{F}$ Epidemiol Community Health 1984;38:156-60.

9 Quanjer PH. Standardized lung function testing. Bull Eur Physiopathol Respir 1983;19(Suppl):45-51.

10 Hunt SM, McEwen J, McKenna SP, Pope C. Subjective health assessments and the perceived outcome of minor health assessments and the perceived outc
surgery. $\mathcal{F}$ Psychosom Res 1984;2:105-14.

11 Yacoub MH, Banner NR, Khaghani A, Fitzgerald M, Madden $\mathrm{B}$, Tsang $\mathrm{V}$, et al. Heart-lung transplant for cystic fibrosis and subsequent domino heart transplantation. $f$ Heart Transplant 1990;9:459-67.

12 Walters S, Britton J, Hodson ME. Demographic and social characteristics of adults with cystic fibrosis in the United Kingdom. BMF 1993;306:53-6. 